Osteoarthritis

\section{Early stages of osteoarthritis: the search for sensitive predictors}

\section{F A Wollheim}

\section{Risk factors, standard radiography, and biomarkers can be used to detect pre-OA}

$\mathrm{O}$ steoarthritis $(\mathrm{OA})$ is perhaps the most common disabling joint affection in developed countries, and consequently a large burden to their health systems. ${ }^{1}$ Furthermore, it is a growing global problem due to increasing life expectancy as well as obesity and smoking, all identified as risk factors for developing knee $\mathrm{OA}$ and knee pain..$^{2}$ Efforts to identify early stages of knee OA are gaining importance because of its prevalence and morbidity and the possible emergence of preventive or modifying interventions. However, radiographic delineation of OA at its onset is not a trivial problem as highlighted by the careful study of Mazzuca et al in this issue of the journal. ${ }^{4}$ In essence the paper shows that radiographically normal is not identical to anatomically normal. Thus the designation of the unilateral nature of knee OA in the Chingford study is not strictly correct. ${ }^{15}$ Nevertheless, the Chingford approach to studying early phases of progression and searching for methods to retard or stop this progression is useful and should be pursued.

\section{"The Chingford approach to study ing knee OA is not strictly correct but, nevertheless useful"}

Recent work has provided new insight into the formation of cartilage and bone during embryonic development. This highly regulated process has bearing on the pathogenesis of OA. Collagen IIA, a splice variant of mature collagen type II, is formed in chondrogenesis. ${ }^{5}$ It is absent in adult healthy cartilage but can again be found in OA. ${ }^{6}$ This observation opens ways to search for biochemical signs of early OA which may be of clinical or scientific use. The problem that faces us is, however, to find the right subjects in a population. They should be still healthy, but predestined to develop OA within a predictable and short time.

\section{ANIMAL MODELS}

Animal models of OA may provide some useful clues. One example is the Finnish model based on controlled mutations of type II collagen. ${ }^{7}$ In this transgenic model joint destruction very similar to human OA develops in close to $100 \%$ of the transgenic animals. The growth factor Sox $9^{8}$ and the structural matrix protein, cartilage oligomeric matrix protein (COMP), , were expressed in the earliest phases. COMP, is a member of the thrombospondin family which was isolated in Dr Heinegård's laboratory in 1992. ${ }^{10}{ }^{11}$ It is expressed in embryonic as well as in normal adult cartilage but at different locations, indicating different functions. An immunoassay of COMP yielded useful information in synovial fluid as well as serum of patients with rheumatoid arthritis (RA) and other arthritides. ${ }^{12}{ }^{13}$ It can provide prognostic information as manifested in the need for total joint replacement comparable with or better than HLA typing in patients with early RA. ${ }^{14}$

\section{CHINGFORD KNEE STUDY}

Attempts to identify OA in the predestructive phase are scarce. The Chingford knee study ${ }^{15}$ selected 58 middle aged woman in whom one knee showed unequivocal OA according to the Kellgren classification while the contralateral knee had no radiographic signs of OA according to the same technique. They then performed follow up studies using this "normal" knee to observe incident OA and identified-for example, obesity as a strong risk factor. One third of all patients developed OA signs in the contralateral knee within two years, applying the KellgrenLawrence classification, where one minimal osteophyte on anteroposterior (AP) radiographs is the required sign distinguishing normal (grade 0) from grade 1 OA. In obese patients almost $50 \%$ developed OA, whereas only $10 \%$ of non-obese patients developed osteophytes. The Indianapolis paper ${ }^{4}$ challenges the Chingford study, and shows convincingly, that a more sensitive radiographic technique discloses discrete osteophytes in a proportion of Chingford normal knee joints already at the initial check. This makes sense, because idiopathic knee $\mathrm{OA}$ is as Mazzuca et al point out in essence a bilateral condition. By using standard standing AP projections as well as lateral and so called skyline projections these authors identified patellofemoral osteophytes in no fewer than $67 \%$ of their patients in the contralateral "Chingford normal" knee. The Chingford model may, however, as stated above, still be useful for studying early intervention or retardation of predictable progression. However when addressing progression rates-for example, in therapeutic intervention, careful standardisation is important. Magnetic resonance imaging has the advantage of directly visualising cartilage and detecting lesions not visible on radiographs, but the method needs further validation and is too expensive for epidemiological studies.

\section{CLINICAL SIGNS}

What other ways are available for identifying subjects with true pre-OA of the knee? One approach is to use simple clinical signs and gather patients with chronic knee pain. The Spenshult cohort study was generated by sending out a simple questionnaire. ${ }^{16}$ The high response rate of over $90 \%$ in this study makes it particularly representative for this population in southern Sweden. Of the 2000 randomly selected subjects in the age group 35-54, 279 had had $>3$ months of knee pain, and 204 were willing to cooperate in a prospective study, which now is well into its second half-decade. Fewer than $15 \%$ had tibiofemoral OA of Kellgren-Lawrence grade 2 or higher. One weakness of this study was that it did not initially assess the patellofemoral joint, because osteophytes in this compartment show a stronger relation to pain than changes in the tibiofemoral joint. ${ }^{17}$ The correlation of osteophytes with signs of cartilage damage as well as with symptoms has been confirmed in several studies and it is better than assessment of joint space narrowing. ${ }^{18} 19$ Therefore it will be of great interest to follow up the Spenshult knee pain cohort and the rate at which radiographic signs of OA develop.

\section{BIOMARKERS}

This population can also be used to assess if biomarkers may be signalling preradiographic OA. COMP concentration in synovial lavage fluid as well as serum COMP were indeed indicators of radiographic progression at the two year follow up, ${ }^{20}{ }^{21}$ and COMP was the most sensitive test for identifying affected subjects with the genetic form of premature OA. ${ }^{22}$ The relation of COMP with progression of OA was recently confirmed in other patient series. ${ }^{23-25}$ 
Furthermore, COMP correlated with joint space narrowing over one year in hip OA in one study. ${ }^{26}$ Interestingly, in this study a bone-specific protein, bone sialoprotein, also correlated with progressive disease. Thus COMP emerges as an important investigational biomarker in the study of early OA. However, the test still requires refinement. COMP is released in the form of fragments which vary depending on diagnosis and perhaps stage of disease, so testing for individual such fragments may yield additional information.

\section{"COMP is an important biomarker in the study of early $\mathrm{OA}^{\prime \prime}$}

Inflammation is now a recognised feature of OA and sensitive tests for $\mathrm{C}$ reactive protein (CRP) show raised levels. ${ }^{27}{ }^{28}$ However CRP is highly nonspecific, and subjects who are obese or have arteriosclerosis also show similar raised levels. It is noteworthy that several studies show no correlation between COMP and CRP, emphasising that COMP is not yet another a marker of inflammation. ${ }^{29} 30$

\section{SUMMARY}

So to sum up there are now three ways for detecting the early phases of OA. The clinician should be familiar with and alert to symptoms and signs of early OA. Risk factors should be a target for attempted prevention. Imaging is the second method. Standard radiography using valid technology is still the preferred method of identifying $\mathrm{OA}$ in populations, and it is interesting that osteophytes are reliable signs of OA in the knee, ${ }^{19}{ }^{31}$ but not in the hip, where joint space narrowing must also be present. ${ }^{32}$ The Mazzuca study emphasises the importance of standardised imaging techniques, but does not exclude the usefulness of studying subjects with asymmetric disease manifestations, as was intended to be done in the Chingford knee study.

Use of biomarkers is the third method. The promising results cited above point to the feasibility of this approach, but the search for more sensitive and specific indicators continues. There is a great demand for better and cheaper markers of OA which can be used as tools to identify patients at risk and assess early effects of interventions. There is a market for fresh ideas, which need to be tested in close collaboration between clinicians and laboratory workers.
Ann Rheum Dis 2003;62:1031-1032

Correspondence to: F A Wollheim, Department of Rheumatology, University of Lund Hospital, S-221 85 Lund, Sweden;

Frank.Wollheim@reum.lu.se

\section{REFERENCES}

1 Peat G, McCarney R, Croft P. Knee pain and osteoarthritis in older adults: a review of community burden and current use of primary health care. Ann Rheum Dis 2001;60:91-7.

2 Hunter DJ, March L, Sambrook PN. Knee osteoarthritis: the influence of environmental factors. Clin Exp Rheumatol 2002;20:93-100.

3 Miranda H, Viikari-Juntura E, Martikainen R, Riihimaki $H$. A prospective study on knee pain and its risk factors. Osteoarthritis Cartilage 2002;10:623-30

4 Mazzuca SA, Brandt KD, German NC Buckwalter KA, Lane KA, Katz BP. Development of radiographic changes in the "Chingford knee" reflects progression or non-standardised positioning of the joint, rather than incident disease. Ann Rheum Dis 2003;62:1061-5.

5 Matyas JR, Sandell U, Adams ME. Gene expression of type II collagens in chondroosteophytes in experimental osteoarthritis. Osteoarthritis Cartilage 1997-5:99-105.

6 Aigner T, Zhu Y, Chansky HH, Matsen FA 3rd, Maloney WJ, Sandell U. Reexpression of type IIA procollagen by adult articular chondrocytes in osteoarthritic cartilage. Arthritis Rheum 1999:42:1443-50.

7 Saamanen AK, Salminen HJ, Dean PB, De Crombrugghe B, Vuorio El, Metsaranta MP. Osteoarthritis-like lesions in transgenic mice harboring a small deletion mutation in type II collagen gene. Osteoarthritis Cartilage 2000;8:248-57.

8 Salminen H, Vuorio E, Saamanen AM. Expression of Sox9 and type IIA procollagen during attempted repair of articular cartilage damage in a transgenic mouse model of osteoarthritis. Arthritis Rheum 2001;44:947-55.

9 Salminen H, Perala M, Lorenzo P, Saxne T, Heinegard D, Saamanen AM, et al. Up-regulation of cartilage oligomeric matrix protein at the onset of articular cartilage degeneration in a transgenic mouse model of osteoarthritis. Arthritis Rheum 2000;43:1742-8

10 Hedbom E, Antonsson P, Hierpe A, Aeschlimann D, Paulsson M, Rosa-Pimentel E, et al. Cartilage matrix proteins. An acidic oligomeric protein (COMP) detected only in cartilage. J Biol Chem 1992;267:6132-6.

11 Oldberg A, Antonsson P, Lindblom K, Heinegård D. COMP (cartilage oligomeric matrix protein) is structurally related to the thrombospondins. J Biol Chem 1992;267:22346-50.

12 Saxne T, Heinegard D. Cartilage oligomeric matrix protein: a novel marker of cartilage turnover detectable in synovial fluid and blood. Br J Rheumatol 1992;31:583-91.

13 Månsson B, Carey D, Alini M, lonescu M, Rosenberg LC, Poole AR, et al. Cartilage and bone metabolism in rheumatoid arthritis. Differences between rapid and slow progression of disease identified by serum markers of cartilage metabolism. J Clin Invest 1995:95:1071-7.

14 Wollheim FA, Eberhardt KB, Johnson U, Saxne T. $\mathrm{HLA} \mathrm{DRB} 1^{*}$ typing and cartilage oligomeric matrix protein (COMP) as predictors of joint destruction in recent-onset rheumatoid arthritis. BrJ Rheumatol 1997:36:847-9.

15 Spector TD, Hart DJ, Byrne J, Harris PA, Dacre JE, Doyle DV. Definition of osteoarthritis of the knee for epidemiological studies. Ann Rheum Dis 1993:52:790-4.

16 Petersson IF, Boegard T, Saxne T, Silman AJ, Svensson B. Radiographic osteoarthritis of the knee classified by the Ahlback and Kellgren \& Lawrence systems for the tibiofemoral joint in people aged 35-54 years with chronic knee pain. Ann Rheum Dis 1997;56:493-6.

17 Cicuttini FM, Baker J, Hart DJ, Spector TD. Association of pain with radiological changes in different compartments and views of the knee joint. Osteoarthritis Cartilage 1996:4:143-7.

18 Spector TD, Hart DJ, Byrne J, Harris PA, Dacre JE, Doyle DV. Definition of osteoarthritis of the knee for epidemiological studies. Ann Rheum Dis 1993;52:790-4.

19 Boegard T, Rudling O, Petersson IF, Jonsson K. Correlation between radiographically diagnosed osteophytes and magnetic resonance detected cartilage defects in the tibiofemoral joint. Ann Rheum Dis 1998:57:401-7.

20 Petersson IF, Sandqvist L, Svensson B, Saxne T. Cartilage markers in synovial fluid in symptomatic knee osteoarthritis. Ann Rheum Dis 1997; 56:64-7.

21 Petersson IF, Boegard T, Svensson B, Heinegard D, Saxne T. Changes in cartilage and bone metabolism identified by serum markers in early osteoarthritis of the knee joint. Br J Rheumatol 1998:37:46-50.

22 Bleasel JF, Poole AR, Heinegard D, Saxne T, Holderbaum $D$, lonescu $M$, et al. Changes in serum cartilage marker levels indicate altered cartilage metabolism in families with the osteoarthritis-related type II collagen gene COL2A1 mutation. Arthritis Rheum 1999;42:39-45

23 Clark AG, Jordan JM, Vilim V, Renner JB, Dragomir AD, Luta $G$, et al. Serum cartilage oligomeric matrix protein reflects osteoarthritis presence and severity: the Johnston County Osteoarthritis Project. Arthritis Rheum 1999:42:2356-64.

24 Dragomir AD, Kraus VB, Renner JB, Luta G, Clark A, Vilim V, et al. Serum cartilage oligomeric matrix protein and clinical signs and symptoms of potential pre-radiographic hip and knee pathology. Osteoarthritis Cartilage 2002;10:687-91.

25 Vilim V, Olejarova M, Machacek S, Gatterova J, Kraus VB, Pavelka K. Serum levels of cartilage oligomeric matrix protein (COMP) correlate with radiographic progression of knee osteoarthritis. Osteoarthritis Cartilage 2002;10:707-13.

26 Conrozier T, Saxne T, Fan CS, Mathieu P, Tron AM, Heinegard D, et al. Serum concentrations of cartilage oligomeric matrix protein and bone sialoprotein in hip osteoarthritis: a one year prospective study. Ann Rheum Dis 1998;57:527-32.

27 Sowers $M$, Jannausch $M$, Stein E, Jamadar D, Hochberg $M$, Lachance L. C-reactive protein as a biomarker of emergent osteoarthritis. Osteoarthritis Cartilage 2002;10:595-601

28 Saxne T, Lindell M, Månsson B, Petersson I, Heinegard D. Inflammation is a feature of the disease process in early knee joint osteoarthritis. Rheumatology (Oxford) (in press).

29 Roux-Lombard P, Eberhardt K, Saxne T, Dayer JM, Wollheim FA. Cytokines, metalloproteinases, their inhibitors and cartilage oligomeric matrix protein: relationship to radiological progression and inflammation in early rheumatoid arthritis. A prospective 5 -year study. Rheumatology (Oxford) $2001 \cdot 40 \cdot 544-51$

30 Wollheim FA. Predictors of joint damage in rheumatoid arthritis. APMIS 1996; 104:81-93.

31 Gilberson EM. Development of periarticular osteophytes in experimentally induced osteoarthritis in the dog. A study using microradiographic, microangiographic, and fluorescent bone-labelling techniques. Ann Rheum Dis 1975;34:12-25.

32 Fredensborg $\mathbf{N}$, Nilsson BE. The joint space in normal hip radiographs. Radiology $1978 ; 126: 325-6$ 